\title{
I Congresso Brasileiro de Organização do Espaço
}

\author{
Dayana Debossan Coelho* \\ Edson Soares Fialho**
}

De 5 a 7 de outubro de 2010, ocorreu na cidade de Rio Claro - SP o I Congresso Brasileiro de Organização do Espaço (CBOE) e o X Seminário de Pós-Graduação em Geografia da UNESP/Rio Claro, tendo como objetivo aprofundar o debate científico referente às relações e dinâmicas das organizações espaciais. O evento foi realizado pelo Programa de Pós-Graduação em Geografia da UNESP/Rio Claro e financiado pela Coordenação de Aperfeiçoamento de Pessoal de Nível Superior (CAPES). Além disso, o encontro foi patrocinado pela Ambiental Expedições. O congresso leva consigo o nome da área de concentração do programa, sendo tema central de vários liames possíveis no saber geográfico.

O evento contou com oito eixos temáticos: História do Pensamento Geográfico, Teoria Espacial e Questões Metodológicas (20 trabalhos); Organização do Espaço Urbano (85 trabalhos); As Dimensões Políticas e Econômicas na Organização do Espaço (57 trabalhos); Organização do Espaço Rural (48 trabalhos); Cultura e Sociedade como Elementos da Organização Espacial (51 trabalhos); Análise das Dinâmicas Ambientais e a Organização Espacial (46 trabalhos); O Estudo de Bacias Hidrográficas no Planejamento e Organização do Espaço (28 trabalhos); As Novas Tecnologias de Informação Geográfica e Geoprocessamento como Ferramentas para o Planejamento e Organização do Espaço (25 trabalhos). Dessa forma, nota-se que o evento recebeu um número de trabalhos significativos (360 no total) apresentados nas modalidades de Comunicação Coordenada e
Sessão Painel. As duas mesas redondas, também com propostas articuladas aos eixos temáticos, foram: "Perspectivas teórico-metodológicas da organização espacial e a relação campo-cidade" e "O estudo integrado de sistemas ambientais: concepções e práticas". Houve duas conferências no evento, sendo que a de abertura e a de encerramento foram proferidas, respectivamente, pelos professores Roberto Lobato Corrêa e Roberto O. Sánchez.

Os alunos da Universidade Estadual Paulista "Júlio de Mesquita Filho" - Campus Rio Claro participaram da construção e organização do evento. Junto a eles estavam os docentes e as instituições de apoio: Instituto de Geociências e Ciências Exatas - UNESP - Rio Claro; Programa de Pós-Graduação em Geografia - UNESP Rio Claro; Departamento de Planejamento Territorial e Geoprocessamento; Departamento de Geografia - UNESP - Rio Claro; Associação de Geografia Teorética - AGETEO; Coordenação de Aperfeiçoamento de Pessoal de Nível Superior (CAPES); Associação Nacional de Pós-Graduação em Geografia (ANPEGE); Fundação para o Desenvolvimento da UNESP - FUNDUNESP; Dipe Car; Ambiental Expedições. Isso demonstra que a Geografia é capaz de agregar e difundir conhecimentos em diversas áreas de pesquisa, trabalhando através de parcerias cientificamente produtivas.

Além disso, o evento efetuou a seleção de artigos para publicação em Edição Especial na Revista Geografia foram selecionados três 
artigos de palestrantes, os de Roberto Lobato Corrêa; Tania Maria Fresca e Roberto O. Sánchez; Os quatorzes demais foram oriundos de artigos enviados por congressistas.

O Congresso foi um sucesso, proporcionando a integração de discentes e docentes, assim como a interdisciplinaridade entre os diversos campos do saber. A proposta deste encontro foi a de criar um debate que proporcionasse a discussão sobre a organização do espaço no período contemporâneo, através de um diálogo sobre o avanço das práticas e dos conhecimentos inerentes ao tema. Sendo assim, o evento cumpriu a promessa de promover a sua realização em âmbito nacional. 